
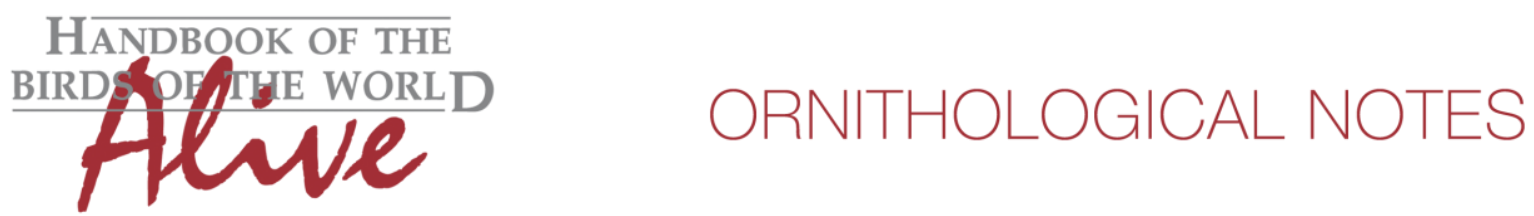

\title{
Notes on the vocalizations of Rusty-crowned Tit-spinetail (Leptasthenura pileata)
}

\section{Peter Boesman}

In the following we briefly analyze and compare voice of the different races of Rustycrowned Tit-spinetail (Leptasthenura pileata). We also try to quantify the extent of any vocal differences using the criteria proposed by Tobias et al. (2010), as a support for taxonomic review.

We have made use of sound recordings available on-line from Xeno Canto (XC).

Race cajabambae is morphologically quite different, and has alternatively been considered a race of $L$. striata (Remsen 2015)

The buzzy chatter of all races of Rusty-crowned Tit-spinetail is however quite different by ear from the more twittering rattle of Streaked Tit-spinetail. Merging race cajabambae into $L$. striata would thus not be logic from a vocal point of view (Fig.1).

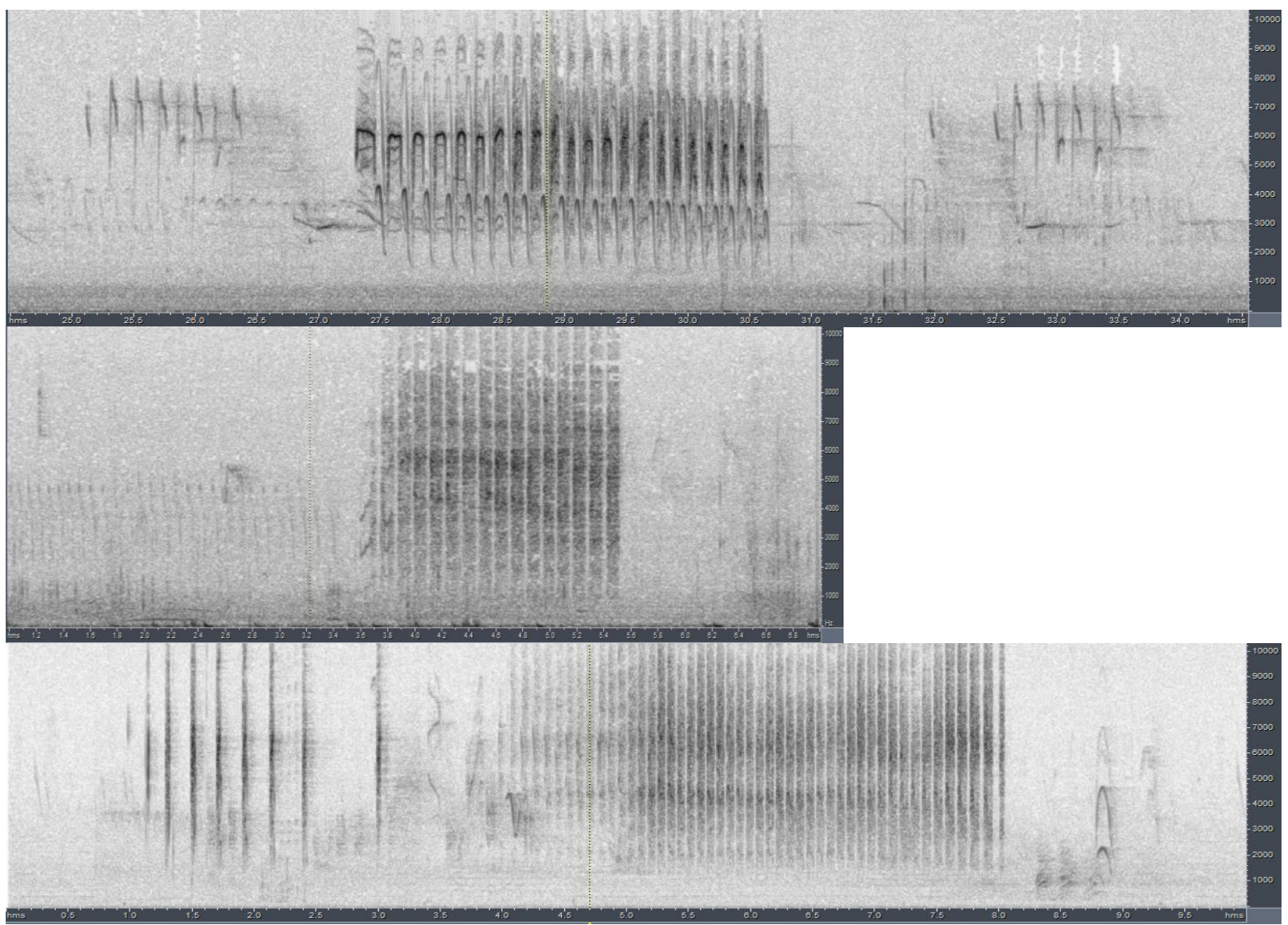

Figure 1: song of L. striata (top), L.p. cajabambae (middle) and L.p. latistriata

Remains to check whether there is significant vocal difference between cajabambae vs. pileata/latistriata. 

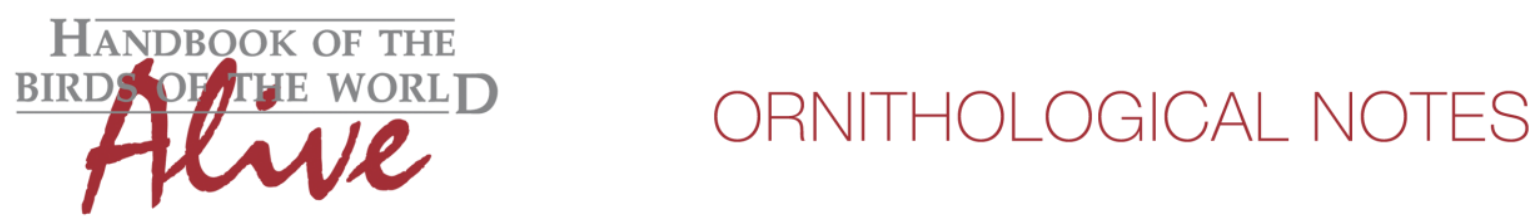

There are very few recordings available on-line of the different races:

cajabambae (song 1 in LNS, 6 in XC)

pileata (only 1 in XC, if correctly identified then probably not song, 0 in LNS)

latistriata (song 2 in XC, 0 in LNS)

Both groups have a similar 'song' consisting of a series of very buzzy, gravely notes.

Measurements:

cajabambae

note length $\quad 0.06-0.09 \mathrm{~s}$

pause $\quad 0.03-0.05 \mathrm{~s}$

pace* $\quad 0.43-0.57 \mathrm{~s}$

* pace here measured as 5 periods, the duration of 5 consecutive notes

\section{latistriata}

note length $\quad 0.05-0.07 \mathrm{~s}$

pause $\quad 0.018-0.038 \mathrm{~s}$

pace $\quad 0.34-0.46 \mathrm{~s}$

There is thus hardly any difference between the two groups. At most, the pace of cajabambae is slightly slower than latistriata, but given the low number of samples this is not much more than a possibility.

This note was finalized on 10th April 2015, using sound recordings available on-line at that moment. We would like to thank in particular the sound recordists who placed their recordings for this species on XC and ML: Peter Boesman, Niels Krabbe, Huw Lloyd, Andrew Spencer and Arnoud van den Berg.

\section{References}

Remsen, J.V., Jr (2015). Rusty-crowned Tit-spinetail (Leptasthenura pileata). In: del Hoyo, J., Elliott, A., Sargatal, J., Christie, D.A. \& de Juana, E. (eds.). Handbook of the Birds of the World Alive. Lynx Edicions, Barcelona. (retrieved from http://www.hbw.com/node/56408 on 9 April 2015).

Tobias, J.A., Seddon, N., Spottiswoode, C.N., Pilgrim, J.D., Fishpool, L.D.C. \& Collar, N.J. (2010). Quantitative criteria for species delimitation. Ibis 152(4): 724-746.

\section{Recommended citation}

Boesman, P. (2016). Notes on the vocalizations of Rusty-crowned Tit-spinetail (Leptasthenura pileata). HBW Alive Ornithological Note 93. In: Handbook of the Birds of the World Alive. Lynx Edicions, Barcelona. (retrieved from http://www.hbw.com/node/931988 on 19 July 2016). 